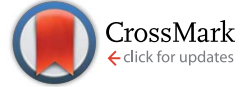

Cite this: RSC AdV., 2017, 7, 17781

Received 24th January 2017

Accepted 15th March 2017

DOI: $10.1039 / \mathrm{c} 7 \mathrm{ra01068 \textrm {k }}$

rsc.li/rsc-advances

\title{
Preparation and catalytic activity of magnetic bimetallic nickel/copper nanowires
}

\author{
Lijuan Sun, $\dagger^{\mathrm{a}}$ Yi Deng, $\dagger^{\mathrm{a}}$ Yuanyi Yang, ${ }^{\mathrm{b}}$ Zhiqiang $\mathrm{Xu},{ }^{a}$ Kenan $X i e^{\mathrm{a}}$ and Li Liao*a
}

Nowadays, 4-nitrophenol (4-NP), one of the most toxic pollutants of waste water, is capturing more attention in the field of sewage disposal. In the present study, bimetallic Ni/Cu nanowires were successfully prepared via a simple approach of liquid phase reduction of $\mathrm{Ni}$ and transmetalation reaction of $\mathrm{Cu}$ assisted by a magnetic field. In addition, the bimetallic nanocomposite was developed as a new catalyst to catalyze the reduction of 4-NP for the first time. The characterization results confirmed that the as-prepared products were bimetallic $\mathrm{Ni} / \mathrm{Cu}$ nanowires with admirable linear structure. Furthermore, the hysteresis loop showed that bimetallic Ni/ Cu nanowires were paramagnetic materials. More importantly, the catalysis results showed that bimetallic $\mathrm{Ni}$ / Cu nanowires possessed appealing catalytic performance and great cycle efficiency compared with other catalysts published in the previous literature. In general, the novel catalyst is able to reduce the product costs significantly resulting from noble-metal free components and a facile preparation approach coupled with commendable catalytic performance. In addition, it is easy to separate from the reaction mixture owing to their intrinsic magnetic properties. Therefore, bimetallic Ni/Cu nanowires hold great potential for industrial effluent disposal purposes.

\section{Introduction}

In recent years, waste water treatment problems have captured extensive attention because water pollution has become more and more serious due to the large amounts of toxic substance emission. It is well-known that 4-nitrophenol (4-NP) is a toxic and hardly degradable organic substance, which always exists in industrial wastewater and domestic sewage due to pesticide abuse and the disposal of dyestuffs or pharmaceuticals. ${ }^{1-3}$ Besides, 4-NP has been listed as a priority pollutant by the U.S. EPA owing to its mutagenic effects and potential carcinogenicity. ${ }^{4}$ 4-Aminophenol (4-AP), the reduction product of 4-NP, however, is a critical medical intermediate and chemical raw material which is extensively employed in the production of dyestuffs, antipyretic analgesics, pharmaceuticals, as well as photographic developers. ${ }^{1-6}$ Therefore, numerous works have committed to solving the reduction reaction of 4-NP.

It is known that 4-AP is fabricated via the catalytic hydrogenation of 4-NP at relatively high temperature and high hydrogen pressure within Pt/C or nano-sized nickel catalyst. ${ }^{7,8}$ Nevertheless, the typical procedure of catalytic hydrogenation contributes to serious safe issue and huge energy consumption. ${ }^{9}$ In recent years, it is of significance that adding late-model catalysts

${ }^{a}$ School of Chemical Engineering, Sichuan University, Chengdu, 610065, China. E-mail: liaolis@scu.edu.cn

${ }^{b}$ Department of Materials Engineering, Sichuan College of Architectural Technology, Deyang 618000, China

$\dagger$ Lijuan Sun and Yi Deng contributed equally to this work. into the reduction of 4-NP under a facile condition has been widely probed. Initially, the pure noble metal nanomaterials like Au nanoparticles ${ }^{10,11}$ and $\mathrm{Ag}$ nanoparticles ${ }^{12}$ are used as the catalysts to catalyze the reduction of 4-NP under mild conditions. But, these materials augment the expenditure of catalysts because of containing noble metal element substance. Moreover, it is difficult for them to recycle after the first use. Afterwards, much effort has been devoted to the nano-scale composite materials containing some precious metals used as catalysts, such as $\mathrm{Cu}$ nanowires-Ag hetero-structures, ${ }^{5}$ magnetic $\mathrm{Ni} / \mathrm{Ag}$ core-shell nanostructure,${ }^{9} \mathrm{Ni} / \mathrm{Au}$ nanostructures,${ }^{13}$ silver bionanocomposite ${ }^{14}$ and nano-gold composite..$^{15}$ In spite of superior catalytic effects and low costs they received, minor catalytic rate and short cycle life hampered the application in the reduction system of 4-NP, furthermore, they still contain noble metal materials leading to high expenditure.

In the present paper, bimetallic $\mathrm{Ni} / \mathrm{Cu}$ nanowires were successfully synthesized and acted as a kind of novel non-noble metal catalyst applying in the system of 4-NP reduction for the first time. The bimetallic $\mathrm{Ni} / \mathrm{Cu}$ nanowires were prepared through a liquid phase reduction strategy with an assisted magnetic field under normal pressure. $\mathrm{NiSO}_{4} \cdot 6 \mathrm{H}_{2} \mathrm{O}, \mathrm{C}_{6} \mathrm{H}_{5} \mathrm{Na}_{3}$ $\mathrm{O}_{7} \cdot 2 \mathrm{H}_{2} \mathrm{O}, \mathrm{N}_{2} \mathrm{H}_{4} \cdot \mathrm{H}_{2} \mathrm{O}$ and $\mathrm{NaBH}_{4}$ in the preparation process of nickel nanowires acted as metal ion precursor, complexant, reductant and initiator respectively. Then the metal replacement method using $\mathrm{CuSO}_{4} \cdot 5 \mathrm{H}_{2} \mathrm{O}$ as copper source was adopted to prepared bimetallic $\mathrm{Ni} / \mathrm{Cu}$ nanowires owing to its safety and simplicity. The products were characterized by X-ray diffraction (XRD), X-ray photoelectron spectroscopy (XPS), scanning electron 
microscopy (SEM), energy dispersive spectrometry (EDS) and high resolution transmission electron microscopy (HRTEM). Finally, magnetic attributes, catalytic properties and cycle activities of bimetallic $\mathrm{Ni} / \mathrm{Cu}$ nanowires were measured by vibrating sample magnetometer (VSM) and ultraviolet-visible spectroscopy, respectively.

\section{Experimental}

\subsection{Materials}

Nickel sulfate hexahydrate $\left(\mathrm{NiSO}_{4} \cdot 6 \mathrm{H}_{2} \mathrm{O}\right)$, trisodium citrate dihydrate $\left(\mathrm{C}_{6} \mathrm{H}_{5} \mathrm{Na}_{3} \mathrm{O}_{7} \cdot 2 \mathrm{H}_{2} \mathrm{O}\right)$, sodium hydroxide $(\mathrm{NaOH})$, hydrazine hydrate $\left(\mathrm{N}_{2} \mathrm{H}_{4} \cdot \mathrm{H}_{2} \mathrm{O}\right)$, sodium borohydride $\left(\mathrm{NaBH}_{4}\right)$, copper sulfate pentahydrate $\left(\mathrm{CuSO}_{4} \cdot 5 \mathrm{H}_{2} \mathrm{O}\right)$ and anhydrous ethanol $\left(\mathrm{C}_{2} \mathrm{H}_{5} \mathrm{OH}\right)$ were purchased from Chengdu Kelong Reagent Co., Ltd (China). 4-Nitrophenol (4-NP) was supplied from Aladdin (Shanghai, China). All the chemicals were of analytical reagent grade without further purification, and all aqueous solutions were prepared with deionized water (D.I. water).

\subsection{Synthesis of bimetallic $\mathrm{Ni} / \mathrm{Cu}$ nanowires}

The whole preparation process of bimetallic $\mathrm{Ni} / \mathrm{Cu}$ nanowires was based on the previous literature ${ }^{16}$ which was published by our group. The beginning molar ratio of $\mathrm{Cu}$ and $\mathrm{Ni}$ was $1: 2$, and its detailed synthetic process was as the following procedure: $0.10 \mathrm{~g}$ of $\mathrm{NiSO}_{4} \cdot 6 \mathrm{H}_{2} \mathrm{O}$ and $0.11 \mathrm{~g}$ of $\mathrm{C}_{6} \mathrm{H}_{5} \mathrm{Na}_{3} \mathrm{O}_{7} \cdot 2 \mathrm{H}_{2} \mathrm{O}$ were dispersed in $60 \mathrm{~mL}$ of deionized water in a $100 \mathrm{~mL}$ polytetrafluoroethylene (PTFE) beaker. When the temperature of the reaction solution reached to $80{ }^{\circ} \mathrm{C}, 0.25 \mathrm{~g}$ of $\mathrm{NaOH}$ was dispersed in the reaction solution with fast stirring until it was completely dissolved. Afterwards, $2 \mathrm{~mL}$ of $80 \mathrm{wt} \% \mathrm{~N}_{2} \mathrm{H}_{4} \cdot \mathrm{H}_{2} \mathrm{O}$ and $50 \mu \mathrm{L}$ alkaline sodium borohydride solution $\left(1.5 \mathrm{~g}\right.$ of $\mathrm{NaBH}_{4}$ and $0.5 \mathrm{~g}$ of $\mathrm{NaOH}$ were dissolved in $20 \mathrm{~mL}$ of deionized water) were added into the solution with tender stirring. The reaction was over until the reaction solution became transparent. Ultimately, the products of Ni nanowires were collected, rinsed three times with deionized water and ethanol respectively.

Next, weighing $0.05 \mathrm{~g} \mathrm{CuSO}_{4} \cdot 5 \mathrm{H}_{2} \mathrm{O}$ dissolved in $50 \mathrm{~mL}$ of deionized water in a glass beaker, and heated it in a water bath with the stationary temperature of $80^{\circ} \mathrm{C}$. When the temperature of the reaction solution reached to $80{ }^{\circ} \mathrm{C}$, Ni nanowires were rapidly added into copper sulfate solution with continued stirring. Subsequently, 2-3 drops of $\mathrm{N}_{2} \mathrm{H}_{4} \cdot \mathrm{H}_{2} \mathrm{O}$ solution were added into the beaker when the surface of the black floc became to be reddish brown, and the color would not change anymore.

Finally, after the reaction solution became transparent, the products were separated from the reaction mixture by neodymium magnets. Similarly, the products of $\mathrm{Ni} / \mathrm{Cu}$ bimetallic nanowires were rinsed three times by deionized water and ethanol respectively. All of these reactions were located between two parallel neodymium magnets $\left(60 \times 30 \times 10 \mathrm{~mm}^{3}\right)$ separated $150 \mathrm{~mm}$ apart. The magnetic intensity inside the reaction solution was approximately $15 \mathrm{mT}$, which was measured by a magnetometer.

\subsection{Characterization}

The composition and crystal structure of the products were examined by X-ray diffraction (XRD, Philips, X'pert Pro MPD) using $\mathrm{Cu} K \alpha$ radiation $(\lambda=0.154249 \mathrm{~nm})$ in the range from $25^{\circ}$ to $80^{\circ}$ with a scanning rate of $4^{\circ} \mathrm{min}^{-1}$. The surface element states of the products were confirmed by X-ray photoelectron spectroscopy (XPS, PHI, ESCALAB MK II spectrometer). The morphology and size of the sample were observed by scanning electron microscopy (SEM, JEOL, JSM-7500F) operating at $10 \mathrm{kV}$ accelerating voltage. The composition and amount of the synthesized nanowires were characterized by energy dispersive spectrometry (EDS, Oxford Instruments, X-Max 51-XMX0019). The crystal structure of the product was surveyed by transmission electron microscope (TEM, Hitachi, H-9000 NAR) operating at $100 \mathrm{kV}$. The magnetic performance of the sample was studied by a vibrating sample magnetometer (VSM, Lake Shore Cryotronics Inc., 7400) using an applied field of up to $2.5 \mathrm{~T}$ at room temperature. The BET specific area of sample was test by automatic surface area and porosimetry system (ASAP, Micromeritics Instrument Corp, 2020 V4.00). The UV-vis absorption spectras were measured by the ultraviolet-visible spectroscopy instrument (UV-VIS, Hitachi, U-3010).

\subsection{Catalytic reduction of 4-nitrophenol}

To study the catalytic activities of bimetallic $\mathrm{Ni} / \mathrm{Cu}$ nanowires and Ni nanowires, the catalytic reduction of 4-NP was carried out per the following procedure: $30 \mathrm{~mL}$ of 4-nitrophenol aqueous solution $\left(1 \times 10^{-4} \mathrm{~mol} \mathrm{~L}^{-1}\right)$ were added into a glass beaker. Afterward, the catalysts of bimetallic $\mathrm{Ni} / \mathrm{Cu}$ nanowires or Ni nanowires $(16 \mathrm{mg})$ were dispersed in the 4-nitrophenol aqueous solution. Then, $10 \mathrm{~mL}$ of freshly prepared alkaline sodium borohydride solution $\left(0.05 \mathrm{~mol} \mathrm{~L}^{-1}\right)$ were introduced into the mixture which act as the reductant, and the time was recorded immediately. The whole catalytic reaction proceeded at room temperature. Finally, $4 \mathrm{~mL}$ of the reaction mixture were transferred into a well-stoppered quartz cuvette, and the absorption spectra was recorded by the UV-vis spectrophotometer every $1 \mathrm{~min}$ at room temperature. ${ }^{11,17}$

\section{Results and discussion}

Fig. 1 revealed XRD patterns of the as-prepared bimetallic $\mathrm{Ni} / \mathrm{Cu}$ nanowires (a) and the same products after ten cycles under same reaction conditions (b). In Fig. 1, three characteristic peaks of face-centered cubic $\mathrm{Ni}$ at the $2 \theta$ values $44.56^{\circ}, 51.92^{\circ}$, $75.44^{\circ}$ corresponded to Miller indices of (111), (200), (220), respectively. Moreover, three characteristic peaks of facecentered cubic $\mathrm{Cu}$ at the $2 \theta$ values $43.38^{\circ}, 50.58^{\circ}, 74.20^{\circ}$ ascribed to Miller indices of (111), (200), (220), respectively. The XRD spectrum of (a) showed the product only included facecentered cubic $\mathrm{Ni}$ and face-centered cubic $\mathrm{Cu}$ without any impurity peak, therefore, the products were confirmed to be bimetallic $\mathrm{Ni} / \mathrm{Cu}$ nanowires. In addition, it was evident that bimetallic $\mathrm{Ni} / \mathrm{Cu}$ nanowires remained their intact phase composition after ten times cycle tests through comparing the XRD patterns of (a) and (b). Therefore, bimetallic $\mathrm{Ni} / \mathrm{Cu}$ 


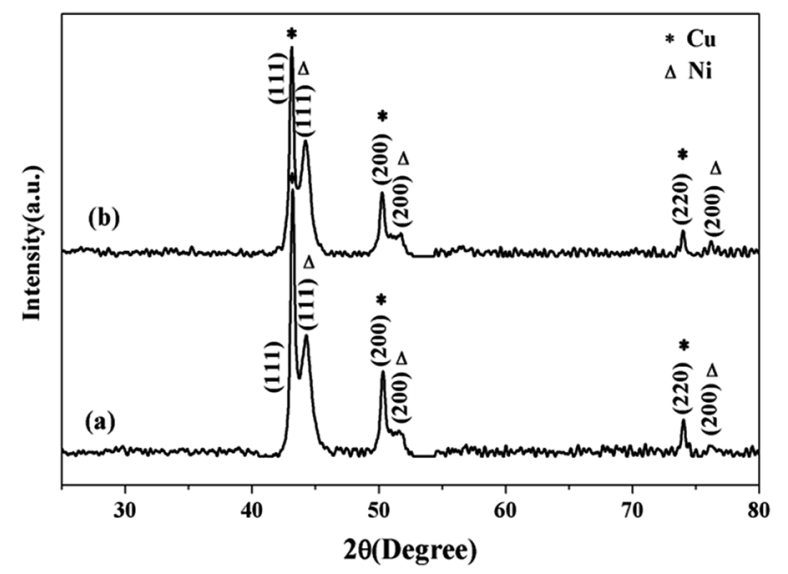

Fig. 1 X-ray diffraction patterns of (a) the as-prepared bimetallic Ni/ Cu nanowires and the same products after ten cycles (b).

nanowires could be used repeatedly, extend the experimental life and reduce costs.

In order to further understand the composition and elemental states in bimetallic $\mathrm{Ni} / \mathrm{Cu}$ nanowires, XPS was employed to obtain the surface information of the products and its results were depicted in Fig. 2. The XPS spectrums of Fig. 2(a) and (b) corresponded to the as-prepared bimetallic $\mathrm{Ni} / \mathrm{Cu}$ nanowires and the same products after ten cycles under the same reaction conditions, respectively. Two peaks at $861.29 \mathrm{eV}$ (Fig. 2(a)) and $861.59 \mathrm{eV}$ (Fig. 2(b)) of Ni 2p XPS spectrum were satellite peak. ${ }^{1}$ The main peaks at $855.72 \mathrm{eV}$ and $852.69 \mathrm{eV}$ of Ni 2p XPS spectrum (Fig. 2(a)) were attributed to the binding energy of $\mathrm{Ni} 2 \mathrm{p}_{3 / 2}$ and $\mathrm{Ni} 2 \mathrm{p}_{1 / 2}$, respectively. The peak at
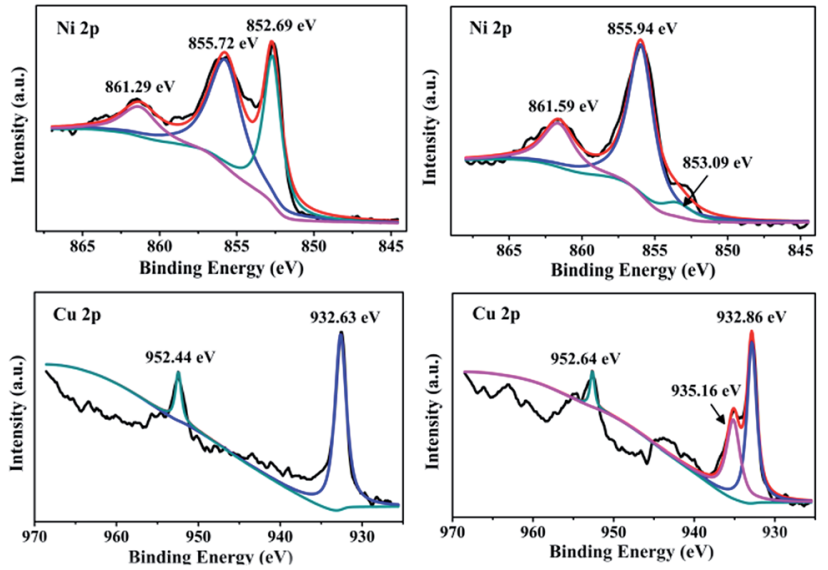

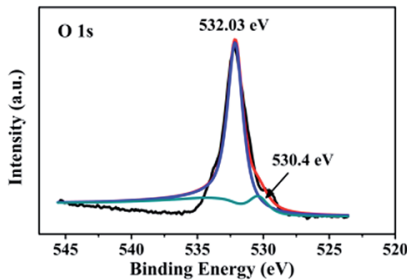

(a)

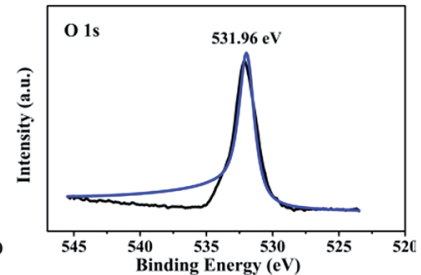

(b)
Fig. 2 XPS spectra of the as-prepared bimetallic Ni/Cu nanowires (a) and the same products after ten cycles (b).
$852.69 \mathrm{eV}$ was assigned to $\mathrm{Ni}^{0}$, and the peak at $855.72 \mathrm{eV}$ verified the existing of $\mathrm{Ni}^{2+}{ }^{2,18}$ Besides, the main peaks at $531.95 \mathrm{eV}$ (Fig. 2(a)) and $532.05 \mathrm{eV}$ (Fig. 2(b)) in O 1s XPS spectrum could be in good agreement with the presence of a hydroxyl group, ${ }^{1}$ which could have been associated with $\mathrm{Ni}(\mathrm{OH})_{2}$ on the surface of sample. The reason for the appearance of $\mathrm{Ni}(\mathrm{OH})_{2}$ was that $\mathrm{NaOH}$ had been added to the preparation of $\mathrm{Ni}$ nanowires. From the $\mathrm{Cu} 2 \mathrm{p}$ spectrum in Fig. 2(a), major contributions from $\mathrm{Cu} 2 \mathrm{p}_{3 / 2}$ at $932.63 \mathrm{eV}$ and $\mathrm{Cu} 2 \mathrm{p}_{1 / 2}$ at $952.44 \mathrm{eV}$ confirmed the presence of $\mathrm{Cu}^{0}{ }^{1}$ And the outermost surface of the sample indicated the absence of divalent copper from the $\mathrm{O} 1 \mathrm{~s}$ spectrum (530.4 eV). ${ }^{1}$ Therefore, the as-prepared sample was bimetallic $\mathrm{Ni} / \mathrm{Cu}$ nanowires with a spot of $\mathrm{Ni}(\mathrm{OH})_{2}$ on the surface. Likewise, two main peaks at $855.94 \mathrm{eV}$ and $853.09 \mathrm{eV}$ of Ni 2p spectrum (Fig. 2(b)) were assigned to $\mathrm{Ni}^{2+}$ and $\mathrm{Ni}^{0}$, respectively. ${ }^{1,18}$ The peaks at $932.86 \mathrm{eV}$ and $952.64 \mathrm{eV}$ of $\mathrm{Cu} 2 \mathrm{p}$ spectrum (Fig. 2(b)) confirmed the presence of $\mathrm{Cu}^{0}$, too. ${ }^{1}$ Moreover, the peak near $935.16 \mathrm{eV}$ of $\mathrm{Cu} 2 \mathrm{p}$ spectrum (Fig. 2(b)) could be assigned to $\mathrm{CuO}^{19}{ }^{19}$ Therefore, part of the copper on the surface of sample were oxidized after ten cycles of catalysis.

The SEM images of the surface morphology of bimetallic Ni/ $\mathrm{Cu}$ nanowires and $\mathrm{Ni}$ nanowires were depicted in Fig. 3. It was obvious that bimetallic $\mathrm{Ni} / \mathrm{Cu}$ nanowires displayed an apparent lineation and its average size of length was about $10 \mu \mathrm{m}$ in Fig. 3(a). Furthermore, its average size of diameter was about $200 \mathrm{~nm}$, which could be easily observed in Fig. 3(b). Therefore, the aspect ratio of bimetallic $\mathrm{Ni} / \mathrm{Cu}$ nanowires was calculated to 50. Similarly, Fig. 3(c) showed that the average diameter of $\mathrm{Ni}$ nanowires was about $200 \mathrm{~nm}$. It was distinct that the surface of bimetallic $\mathrm{Ni} / \mathrm{Cu}$ nanowires was extremely rough compared to Ni nanowires because of existing lots of bumps, which could be seen from the Fig. 3(b) and (c).

To confirm the content of $\mathrm{Ni}$ and $\mathrm{Cu}$, the elements of bimetallic $\mathrm{Ni} / \mathrm{Cu}$ nanowires were examined by energy dispersive spectrometry (EDS). Fig. 4(a) was the selected area of bimetallic $\mathrm{Ni} / \mathrm{Cu}$ nanowires, and Fig. 4(b) was the detailed element spectrum corresponding to the selected area. The Fig. 4(a) exhibited that as-prepared sample contained nickel element as well as copper element, which was consistent with XRD patterns. Besides, the weight percent of $\mathrm{Ni}$ and $\mathrm{Cu}$ were $68.65 \%, 31.35 \%$, respectively, and the atom percent of $\mathrm{Ni}$ and $\mathrm{Cu}$ were $70.33 \%$, $29.67 \%$, respectively. The silicon peak and gold peak were left out from the calculation of the elementary composition because they were originated from the silicon wafer substrate and gold sputtering, respectively. Moreover, the elemental mapping profiles of $\mathrm{Ni}$ (Fig. 4(c)) and $\mathrm{Cu}$ (Fig. 4(d)) further confirmed the presence of nickel and copper as well as their uniform distribution patterns.
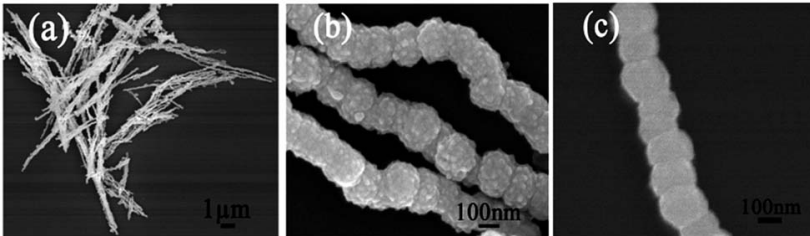

Fig. 3 SEM images of bimetallic Ni/Cu nanowires at different magnification (a), (b), and Ni nanowires at high magnification (c). 

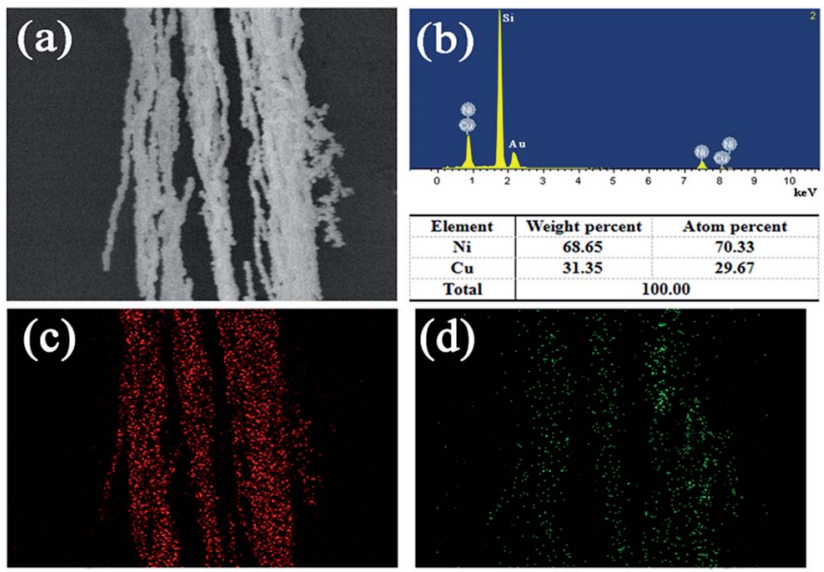

Fig. 4 EDS spectrum of bimetallic Ni/Cu nanowires (a) and different element content (b), and elemental mapping profile of $\mathrm{Ni}(\mathrm{c})$ and $\mathrm{Cu}$ (d).

The TEM patterns of the bimetallic $\mathrm{Ni} / \mathrm{Cu}$ nanowires in Fig. 5(a-c) indicated that the as-prepared sample presented great lineation with an average diameter of about $200 \mathrm{~nm}$ in line with SEM observation. The HRTEM pattern in Fig. 5(d) showed that the lattice distance of $\mathrm{Ni}$ was about $0.20 \mathrm{~nm}$, which was in accord with the (111) lattice plane of face-centered cubic Ni. Furthermore, the lattice distance of $\mathrm{Cu}$ was about $0.21 \mathrm{~nm}$, which was consistent with the (111) lattice plane of facecentered cubic $\mathrm{Cu}$. Hence, the components of bimetallic $\mathrm{Ni}$ / $\mathrm{Cu}$ nanowires were further confirmed through these results.

The catalytic activities of the bimetallic $\mathrm{Ni} / \mathrm{Cu}$ nanowires were examined in the system of the reduction of 4-NP to 4-AP, and the results were displayed in Fig. 6 . It was easy to see that in Fig. 6(a) the 4-NP had an absorption peak at $317 \mathrm{~nm}$, however, when freshly prepared alkaline sodium borohydride solution was added at room temperature, the absorption peak immediately shifted to $400 \mathrm{~nm} .^{20}$ The reason for this change was that 4NP shifted to 4-nitrophenolate ions in alkaline medium. ${ }^{12}$ This

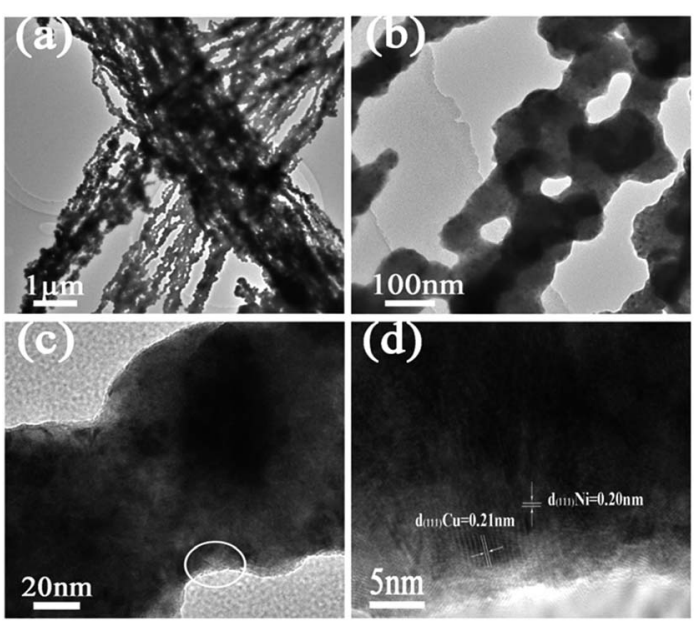

Fig. 5 TEM patterns of bimetallic Ni/Cu nanowires with different magnifications $(a-c)$, HRTEM pattern of bimetallic Ni/Cu nanowires (d) was taken from the white circle in (c).

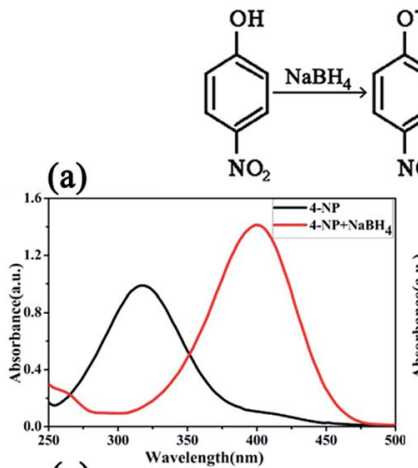

(c)
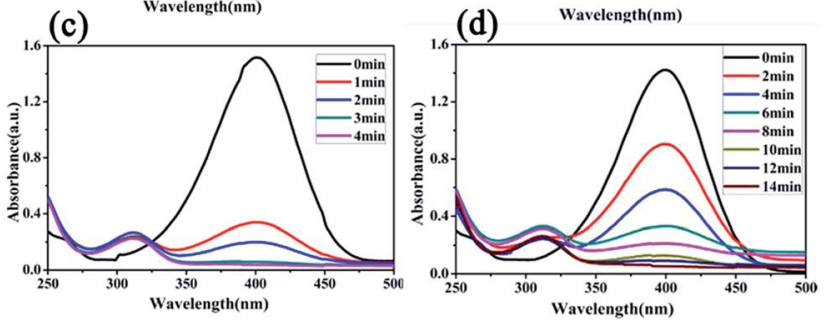

Fig. 6 UV-vis spectra of the 4-NP reduction without any catalyst (a and b), and with the bimetallic $\mathrm{Ni} / \mathrm{Cu}$ nanowires (c), as well as $\mathrm{Ni}$ nanowires $(d)$.

mixture was placed for three months without any alteration because the 4-NP is stable and the reduction of 4-NP is difficult without any catalysts as shown in Fig. 6(b). ${ }^{21}$ Nevertheless, when the catalyst was introduced into the mixture, the color of the mixture was changed quickly. In order to precisely investigate the catalytic performance of bimetallic $\mathrm{Ni} / \mathrm{Cu}$ nanowires for the 4-NP reduction, the reaction process was clearly monitored and the result was presented in Fig. 6(c). Moreover, Fig. 6(c) exhibited the alteration of absorption maximum at different time with the catalyst of bimetallic $\mathrm{Ni} / \mathrm{Cu}$ nanowires. As the extension of time, plenty of reduction product of 4-AP appeared in the solution with an absorption peak at about $300 \mathrm{~nm}$, so it could be observed easily in Fig. 6(c) that the peak at $400 \mathrm{~nm}$ gradually decreased accompanied with the increase of a new peak at about $300 \mathrm{~nm} .{ }^{22}$ After about $4 \mathrm{~min}$, the absorption peak of 4-NP disappeared with the catalyst of bimetallic $\mathrm{Ni} / \mathrm{Cu}$ nanowires. Besides, the convert ratio had been calculated to be $98.65 \%$ after four minutes reaction. Furthermore, the catalytic performance of $\mathrm{Ni}$ nanowires for the 4-NP reduction was studied, and the result was showed in Fig. 6(d). It was evident that the absorption peak of 4-NP disappeared with the catalyst of Ni nanowires after $14 \mathrm{~min}$, and the final reaction convert ratio was $97.49 \%$.

The kinetic of the reduction of 4-NP was modeled in terms of a Langmuir-Hinshelwood mechanism, where all reactants needed to be adsorbed on the surface before reaction. ${ }^{23}$ This reaction rate did not depend on the concentration of $\mathrm{NaBH}_{4}$ on account of high concentrations of $\mathrm{NaBH}_{4}$ compared to low concentrations of $4-\mathrm{NP}$, so it was verified to be pseudo-first order reaction. ${ }^{24,25}$ Fig. 7 showed the plots of $\ln \left(A_{t} / A_{0}\right) v s$. time for the catalytic reduction of 4-NP using $\mathrm{NaBH}_{4}$ in the presence of $\mathrm{Ni}$ nanowires and bimetallic $\mathrm{Ni} / \mathrm{Cu}$ nanowires with different molar ratio. In addition, Fig. 7 illustrated this reduction 


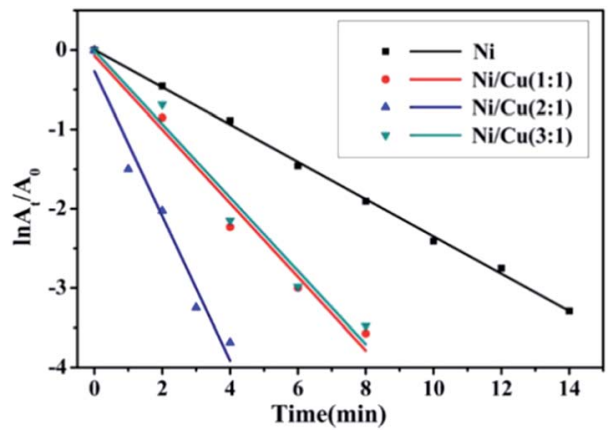

Fig. 7 Plots of $\ln \left(A_{t} / A_{0}\right)$ versus time for the catalytic reduction of 4-NP using $\mathrm{NaBH}_{4}$ in the presence of $\mathrm{Ni}$ nanowires and bimetallic $\mathrm{Ni} / \mathrm{Cu}$ nanowires with different molar ratio.

reaction displayed a good linearity, and the correlation coefficient of $R^{2}$ value (the $R^{2}$ value of $\mathrm{Ni}, \mathrm{Ni} / \mathrm{Cu}(1: 1), \mathrm{Ni} / \mathrm{Cu}(2: 1)$, $\mathrm{Ni} / \mathrm{Cu}(3: 1)$ were equal to $0.99821,0.97223,0.96434,0.96366$, respectively) suggested that there was a great agreement between the experimental values and the predicted values. Besides, the rate constant for Ni nanowires as well as bimetallic $\mathrm{Ni} / \mathrm{Cu}$ nanowires with the beginning molar ratio of $1: 1,2: 1$, $3: 1$ were calculated to be $0.23524 \mathrm{~min}^{-1}, 0.46446 \mathrm{~min}^{-1}$, $0.9118 \mathrm{~min}^{-1}, 0.46255 \mathrm{~min}^{-1}$, respectively, from the slope of the curve in Fig. 7 . The observed results clearly demonstrated that the catalytic rate of bimetallic $\mathrm{Ni} / \mathrm{Cu}$ nanowires with the beginning molar ratio of $2: 1$ was more efficient than others. It was well known that the enhanced catalytic activity of bimetallic $\mathrm{Ni} / \mathrm{Cu}$ nanowires compared to $\mathrm{Ni}$ nanowires was attributed to the presence of synergistic effect of the binary components. In addition, according to the SEM images, the surface of bimetallic $\mathrm{Ni} / \mathrm{Cu}$ nanowires was rougher than Ni nanowires. Moreover, the bimetallic $\mathrm{Ni} / \mathrm{Cu}$ nanowires with molar ratio of $1: 1 \mathrm{might}$ have formed the cladding structures because of excessive copper. And this structure made the nickel wrapped inside, which meant nickel did not play a catalytic role for the reaction system. Furthermore, the bimetallic $\mathrm{Ni} / \mathrm{Cu}$ nanowires with molar ratio of $3: 1$ had the lower catalytic performance than bimetallic $\mathrm{Ni} /$ $\mathrm{Cu}$ nanowires with molar ratio of $2: 1$ due to a small quantity of copper. The existence of a small quantity of copper decreased the amount of active site of binary components and made the surface of sample less rough. In conclusion, the bimetallic Ni/ $\mathrm{Cu}$ nanowires with the beginning molar ratio of $2: 1$ were the most efficient catalysts compared to Ni nanowires, $\mathrm{Ni} / \mathrm{Cu}(1: 1)$ nanowires and $\mathrm{Ni} / \mathrm{Cu}(3: 1)$ nanowires.

The magnetic hysteresis loop of bimetallic $\mathrm{Ni} / \mathrm{Cu}$ nanowires was measured at room temperature under an applied magnetic field of up to $20000 \mathrm{Oe}$, and the variation of the magnetization versus magnetic field was showed in Fig. 8. The coercivity $\left(H_{\mathrm{c}}\right)$, saturation magnetization $\left(M_{\mathrm{S}}\right)$ and remnant magnetization $\left(M_{\mathrm{r}}\right)$ were $295.58 \mathrm{Oe}, 23.06 \mathrm{emu}^{-1}$ and $6.45 \mathrm{emu} \mathrm{g}^{-1}$, respectively. The appearance of hysteresis loop confirmed that bimetallic $\mathrm{Ni} / \mathrm{Cu}$ nanowires possessed paramagnetic property. ${ }^{26}$ Therefore, bimetallic $\mathrm{Ni} / \mathrm{Cu}$ nanowires could be recycled from solution after reaction by applying an external magnetic field.

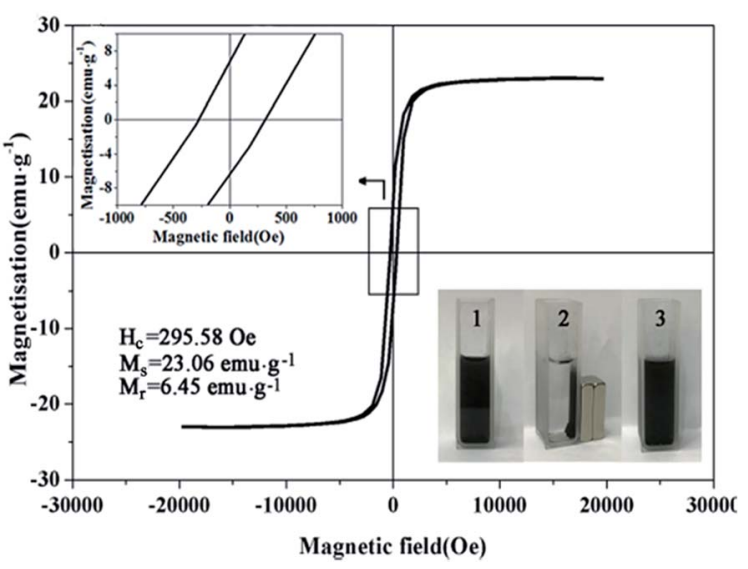

Fig. 8 Magnetic hysteresis loop of bimetallic $\mathrm{Ni} / \mathrm{Cu}$ nanowires, repeatability tests for 10 cycles of 4-NP reduction under the same reaction conditions with catalyst of bimetallic $\mathrm{Ni} / \mathrm{Cu}$ nanowires.

Because bimetallic $\mathrm{Ni} / \mathrm{Cu}$ nanowires possessed magnetism, they could be separated easily from the reaction mixture by providing a magnetic field so that they were able to be reused easily. In order to investigate the reusability of bimetallic $\mathrm{Ni} / \mathrm{Cu}$ nanowires, cycle tests were showed in Fig. 9. It was apparent that the convert ratio of first cycle was a little low in comparison to that of second cycle owing to the activation of catalyst. As the number of cycles increased, the convert ratio of this reaction decreased slightly due to adsorbing some substances from reaction system on the surface of the products. After ten cycles at room temperature proceeded, the convert ratio was still 92.25\% remaining high catalytic performance. The results demonstrated that the bimetallic $\mathrm{Ni} / \mathrm{Cu}$ nanowires possessed excellent durability for the 4-NP reduction.

Table 1 compared the rate constants $(k)$, activity factor $(K)$, number of cycles and convert ratio of bimetallic $\mathrm{Ni} / \mathrm{Cu}$ nanowires and other catalysts reported from other work for the 4-NP reduction. Clearly, it showed that bimetallic $\mathrm{Ni} / \mathrm{Cu}$ nanowires possessed more enhanced performance like higher rate constant and longer cycle life than other noble metal composite nanomaterial, such as $\mathrm{Fe}_{3} \mathrm{O}_{4} @ \mathrm{SiO}_{2}-\mathrm{Ag} \mathrm{MNPs},{ }^{27} \mathrm{Ni} / \mathrm{Ag}$ core-shell

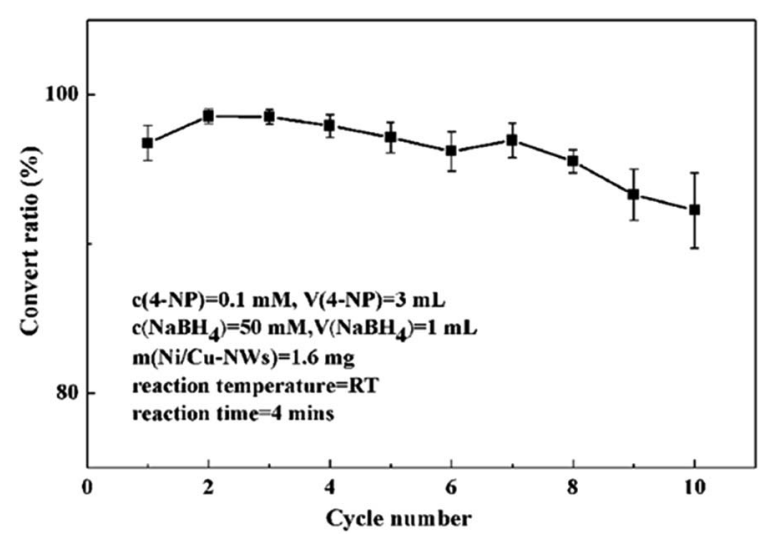

Fig. 9 Repeatability tests for 10 cycles of 4-NP reduction under the same reaction conditions with catalyst of bimetallic Ni/Cu nanowires. 
Table 1 Comparison of rate constants $(k)$, activity factor $(K)$, number of cycles and convert ratio

\begin{tabular}{|c|c|c|c|c|}
\hline Samples & Quality/mg & $\begin{array}{l}\text { Rate constant } \\
(k) / \min ^{-1}\end{array}$ & $\begin{array}{l}\text { Activity factor } \\
(K) / \mathrm{min}^{-1} \mathrm{mg}^{-1}\end{array}$ & $\begin{array}{l}\text { Number of cycles } \\
\text { and convert ratio }\end{array}$ \\
\hline Magnetic Ni/Cu bimetallic NWs & 1.6 & 0.9118 & 0.5699 & $10(92 \%)$ \\
\hline $\mathrm{Ni} / \mathrm{Ag}$ core-shell nanostructures ${ }^{9}$ & 0.5 & 0.13 & 0.26 & - \\
\hline $\mathrm{Ni} / \mathrm{Au}$ nanostructures ${ }^{13}$ & 8 & 0.076 & 0.0095 & - \\
\hline Bimetallic $\mathrm{Ag}-\mathrm{Au} \mathrm{NWs}^{28}$ & 0.25 & 0.228 & 0.912 & - \\
\hline
\end{tabular}

nanostructures, ${ }^{9} \mathrm{Ni} / \mathrm{Au}$ nanostructures, ${ }^{13}$ bimetallic $\mathrm{Ag}-\mathrm{Au}$ $\mathrm{NWs}^{28}$ and silver bionanocomposite. ${ }^{14}$

According to the previous literatures, the 4-nitrophenolate ions were adsorbed on the surface of bimetallic $\mathrm{Ni} / \mathrm{Cu}$ nanowires during the initial catalytic reaction..$^{29,30}$ Therefore, the specific surface area would directly affect the catalytic performance. In this study, the BET surface area of bimetallic Ni/Cu nanowires was $11.3764 \mathrm{~m}^{2} \mathrm{~g}^{-1}$. Besides, the catalytic activity was closely related to the proportion of surface atoms located on the corners and edges of the metal nanocomposites. ${ }^{31}$ As a consequence, bimetallic Ni/ $\mathrm{Cu}$ nanowires with rough surface possessed preeminent catalytic rate owing to high fraction of corners and edges. Synergistic effect of duplex metal was another vital factor contributing to enhance the catalytic activity of bimetallic $\mathrm{Ni} / \mathrm{Cu}$ nanowires. ${ }^{26,32}$ As is well known, copper nanowires ${ }^{5}$ and nickel nanowires ${ }^{13}$ all played a catalytic role for the reduction of 4-NP. Moreover, a multitude of studies showed that only a small variation in a local electronic structure on the interface between $\mathrm{Ni}$ and $\mathrm{Cu}$ relative to their monometal could contribute to the enhancement of catalytic performance. ${ }^{33,34}$ Although bimetallic $\mathrm{Ag}-\mathrm{Au}$ NWs possessed higher activity factor $(K)$ than bimetallic $\mathrm{Ni} / \mathrm{Cu}$ nanowires, they belonged to precious metal materials, which increased the cost in industrial production. Besides, bimetallic Ag-Au NWs were difficult to separate from the mixture, and there was no cyclic test in the ref. 28 of bimetallic $\mathrm{Ag}-\mathrm{Au}$ NWs. Therefore, bimetallic $\mathrm{Ni} / \mathrm{Cu}$ nanowires had a higher catalytic activity than most other noble metal nanomaterials listed in Table 1 .

\section{Conclusions}

In summary, magnetic bimetallic $\mathrm{Ni} / \mathrm{Cu}$ nanowires were successfully synthesized by solution phase reduction of $\mathrm{Ni}$ and metal replacement reaction of $\mathrm{Cu}$ under the magnetic field. The characterization results proved that products were bimetallic $\mathrm{Ni} / \mathrm{Cu}$ nanowires with aspect ratio of 50 and rough surface. They consisted of non-noble metal materials, which can reduce the expenditure. Subsequently, bimetallic $\mathrm{Ni} / \mathrm{Cu}$ nanowires acted as a new kind of catalyst applied in the system of 4-NP reduction for the first time. And the catalysis results exhibited that bimetallic $\mathrm{Ni} / \mathrm{Cu}$ nanowires have excellent catalytic activity and appealing cycle performance. The rate constant of this catalytic reaction was determined to be $0.0154 \mathrm{~s}^{-1}$, and after reacting for four minutes, the convert ratio had been calculated to be $98.65 \%$. Besides, the convert ratio of this catalytic reaction still remained $92.25 \%$ after ten cycles under the same conditions.
Moreover, the hysteresis loop indicated that bimetallic $\mathrm{Ni} / \mathrm{Cu}$ nanowires possess paramagnetism, thus it is easy to separate the catalysts from the reaction mixture through an external magnetic field, indicating it can be reused easily. Therefore, magnetic bimetallic Ni/Cu nanowires have a great application for sewage treatment yield. In order to enhance the applicability of magnetic bimetallic $\mathrm{Ni} / \mathrm{Cu}$ nanowires in field of waste water treatment, catalyzing the reaction of nitrophenol derivatives will be the subsequent research.

\section{Acknowledgements}

This work was funded by the National Natural Science Foundation of China (No. 50904046).

\section{References}

1 S. Ghosh, R. Das, I. H. Chowdhury, P. Bhanja and M. K. Naskar, RSC Adv., 2015, 5, 101519-101524.

2 R. Prasad, M. K. Lolakshi and B. R. Bhat, Synth. Met., 2016, 219, 26-32.

3 A. D. Verma, R. K. Mandal and I. Sinha, Catal. Lett., 2015, 145, 1885-1892.

4 S. P. Sun and A. T. Lemley, J. Mol. Catal. A: Chem., 2011, 349, 71-79.

5 Y. Sun, F. Y. Zhang, L. Xu, Z. L. Yin and X. Y. Song, J. Mater. Chem. A, 2014, 2, 18583-18592.

6 W. Che, Y. H. Ni, Y. X. Zhang and Y. Ma, J. Phys. Chem. Solids, 2015, 77, 1-7.

7 M. J. Vaidya, S. M. Kulkarni and R. V. Chaudhari, Org. Process Res. Dev., 2003, 7, 202-208.

8 Y. Du, H. L. Chen, R. Z. Chen and N. P. Xu, Appl. Catal., A, 2004, 277, 259-264.

9 S. Senapati, S. K. Srivastava, S. B. Singh and H. N. Mishra, J. Mater. Chem., 2012, 22, 6899-6906.

10 Y. C. Chang and D. H. Chen, J. Hazard. Mater., 2009, 165, 664-669.

11 S. S. Kumar, C. S. Kumar, J. Mathiyarasu and K. L. Phani, Langmuir, 2007, 23, 3401-3408.

12 N. Pradhan, A. Pal and T. Pal, Colloids Surf., A, 2002, 196, 247-257.

13 S. Sarkar, A. K. Sinha, M. Pradhan, M. Basu, Y. Negishi and T. Pal, J. Phys. Chem. C, 2011, 115, 1659-1673.

14 K. B. Narayanan and N. Sakthivel, Bioresour. Technol., 2011, 102, 10737-10740. 
15 K. B. Narayanan and N. Sakthivel, J. Hazard. Mater., 2011, 189, 519-525.

16 H. Wang, X. Y. Li, M. Li, K. N. Xie and L. Liao, Beilstein J. Nanotechnol., 2015, 6, 1268-1271.

17 Y. X. Fang and E. K. Wang, Nanoscale, 2013, 5, 1843.

18 H. W. Nesbitt, D. Legrand and G. M. Bancroft, Phys. Chem. Miner., 2000, 27, 357-366.

19 P. Mao, L. Qi, X. D. Liu, Y. Liu, Y. Jiao, S. W. Chen and Y. Yang, J. Hazard. Mater., 2017, 328, 21-28.

20 M. Miranzadeh and M. Z. Kassaee, Chem. Eng. J., 2014, 257, 105-111.

21 L. Zhang, Z. Liu, Y. Wang, R. Xie, X. J. Ju, W. Wang, L. G. Lin and L. Y. Chu, Chem. Eng. J., 2017, 309, 691-699.

22 H. H. Lu, H. B. Yin, Y. M. Liu, T. S. Jiang and L. B. Yu, Catal. Commun., 2008, 10, 313-316.

23 D. K. Bhui and A. Misra, Carbohydr. Polym., 2012, 89, 830835.

24 S. Jana, S. Ghosh, S. Nath, S. Pande, S. Praharaj, S. Panigrahi, S. Basu, T. Endo and T. Pal, Appl. Catal., A, 2006, 313, 41-48. 25 Y. Imura, K. Tsujimoto, C. Morita and T. Kawai, Langmuir, 2014, 30, 5026-5030.
26 S. Senapati, S. K. Srivastava, S. B. Singh and K. Biswas, Cryst. Growth Des., 2010, 10, 4068-4075.

27 X. Y. Du, J. He, J. Zhu, L. J. Sun and S. S. An, Appl. Surf. Sci., 2012, 258, 2717-2723.

28 H. T. Fu, X. H. Yang, X. C. Jiang and A. B. Yu, Langmuir, 2013, 29, 7134-7142.

29 K. Hayakawa, T. Yoshimura and K. Esumi, Langmuir, 2003, 19, 5517-5521.

30 H. Koga, Y. Umemura and T. Kitaoka, Catalysts, 2011, 1, 6982.

31 H. Zhang, M. S. Jin, Y. J. Xiong, B. K. Lim and Y. N. Xia, Acc. Chem. Res., 2013, 46, 1783-1794.

32 M. Han, S. L. Liu, L. Y. Zhang, C. Zhang, W. W. Tu, Z. H. Dai and J. C. Bao, ACS Appl. Mater. Interfaces, 2012, 4, 6654-6660. 33 X. Q. Huang, Y. J. Li, H. L. Zhou, X. Zhong, X. F. Duan and Y. Huang, Chem.-Eur. J., 2012, 18, 9505-9510.

34 H. F. Zarick, W. R. Erwin, J. Aufrecht, A. Coppola, B. R. Rogers, C. L. Pint and R. Bardhan, J. Mater. Chem. A, 2014, 2, 7088-7098. 